\title{
INDUCTION OF AN IMMUNE RESPONSE TO TRANSMISSIBLE GAS- TROENTERITIS CORONAVIRUS USING VECTORS WITH ENTERIC TROPISM
}

\author{
Cristian Smerdou ${ }^{1}$, Juan M. Torres ${ }^{1}$, Carlos M. Sánchez ${ }^{1}$, Carlos \\ Suñé ${ }^{1}$, Inés M. Antón ${ }^{1}$, Miguel Medina ${ }^{1}$, Joaquin Castilla ${ }^{1}$, Frank L. \\ Graham $^{2}$, and L. Enjuanes ${ }^{1}$ \\ 1 Centro Nacional de Biotecnología \\ CSIC - Universidad Autónoma \\ Canto Blanco. 28049 Madrid, Spain \\ 2 Department of Biology, McMaster University \\ Hamilton, Ontario, Canada L8S4K1
}

\section{INTRODUCTION}

Transmissible gastroenteritis virus (TGEV) causes high mortality in neonatal pigs ${ }^{1}$. TGEV has four structural proteins: the spike (S), the nucleoprotein $(\mathrm{N})$, the membrane protein $(\mathrm{M})$, and the small membrane (SM) protein. Protein $S$ is the major inducer of TGEV neutralizing antibodies. Four antigenic sites (A, B, C, and D) have been defined in S protein $^{2,3,4}$. These sites have been located in the amino-end half of $S$ protein. The precise amino acids contributing to the formation of these sites were described 5 . Site $\mathrm{A}$ is antigenically dominant and has been divided into three antigenic subsites: $\mathrm{Aa}, \mathrm{Ab}$, and $\mathrm{Ac}$. Sites $A$ and $D$, and in minor extent site $B$, have been involved in the neutralization of TGEV. Glycosylation dependent (sites A and B) and independent (sites D and C) antigenic determinants have been defined.

Protection against TGE requires lactogenic immunity, which is best induced by presentation of selected antigens to the immune system in gut associated lymphoid tissues (GALT). We have focused on the selection of antigenic determinants involved in protection, and on their expression in GALT using Salmonella typhimurium and adenovirus based vectors with tropism for Peyer's patches 6,7

\section{MATERIALS AND METHODS}

\section{Cells, viruses, and monoclonal antibodies}

The PUR46 strain of TGEV was used. The virus was grown, purified, and titrated on swine testicle (ST) cells, as previously described ${ }^{3}$. The MAbs used were specific for TGEV and their characteristics have been described 2,8 
A

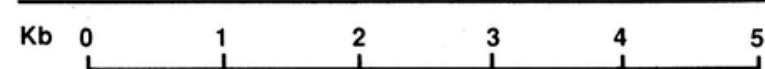

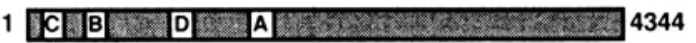

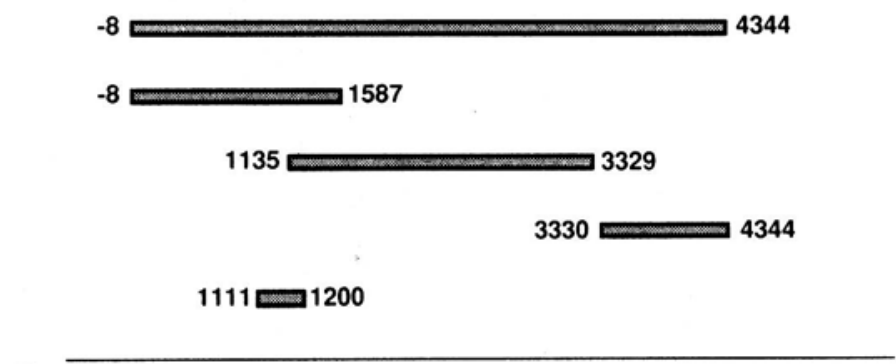

B

SITE D

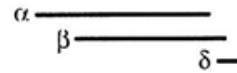

a. ISCYTVSDSSFFSYGEIPFGVTDGPRYCYV

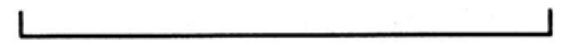

b. C`SDSSFFSYGEIPFG

c. SFFSYGEI-SFFSYGEI-C*

FIGURE 1. Transmissible gastroenteritis virus $S$ gene fragments selected for expression. A. Diagrammatic representation of the $S$ gene of TGEV showing the approximate location of the four antigenic sites (thick bar with capital letters). The segments of the $S$ gene cloned into Salmonella have been represented by thin bars. Numbers at both ends indicate the flanking residues cloned into Salmonella. B. The sequences of three peptides $(\mathrm{a}, \mathrm{b}$, and $\mathrm{c})$ which include site D are shown. The core structure recognized by site D specific MAbs 57.51, 57.57 , and $8 \mathrm{D} . \mathrm{H8}$, have been overlined ( $\alpha, \beta$, and $\delta$, respectively) $5,12{ }^{*}$, indicates cysteine residues not present in the viral sequence.

Radioimmunoassay (RIA), virus neutralization, and TGEV gene cloning

The procedures for RIA and neutralization have been described ${ }^{3}$. TGEV genes were cloned into Bluescript $\mathrm{SK}^{-}$plasmids ${ }^{5,9}$.

Cloning and expression of TGEV $S$ gene fragments in S. typhimurium and adenoviruses

Expression in avirulent forms of $S$. typhimurium $\Delta c y a, \Delta c r p, \Delta a s d$, developed by $\mathrm{R}$. Curtiss III group 6 , was made by cloning the whole $S$ gene or the indicated fragments, into 
TABLE 1. Recombinant $a s d^{+}$plasmids expressing TGEV S protein fragments

\begin{tabular}{|c|c|c|c|c|}
\hline \multirow{2}{*}{$\begin{array}{l}\text { Recombinant } \\
\text { plasmid }\end{array}$} & \multirow{2}{*}{$\begin{array}{l}\text { asd } \\
\text { vector }\end{array}$} & \multirow{2}{*}{$\begin{array}{l}\text { S-gene fragment } \\
\text { cloned }\end{array}$} & \multicolumn{2}{|c|}{$\begin{array}{l}\text { Expression in } \\
\text { S. typhimurium strain }\end{array}$} \\
\hline & & & $\chi 3730$ & $\chi 3987$ \\
\hline pYATS - 1 & pYA292 & $-8-1587$ & +++ & +++ \\
\hline pYATS - 2 & $"$ & $1135-3329$ & +++ & $+1-$ \\
\hline pYATS - 3 & $"$ & $3330-4628$ & - & - \\
\hline pYATS - 4 & $"$ & $-8-4628$ & ++ & + \\
\hline pYALT-D & pYA3048 & $1111-1200$ & +++ & +++ \\
\hline
\end{tabular}

a. PstI site in S gene was taken from Bluescript vector polylinker.

plasmid pYA292. These plasmids were transfected into Escherichia coli $\chi 6097 \mathrm{~F}^{\prime} \Delta$ asd $\Delta[$ pro-lac $] \phi 80$ d lacZ $\triangle \mathrm{M} 15$. Plasmid DNA was modified by transforming an intermediate $S$. typhimurium $\chi 3730 \Delta$ asd hsdSA $h s d S B$ defective in restriction enzymes. Modified plasmids were transfected into $S$. typhimurium $\chi 3987 \Delta$ asd $\Delta$ cya $\Delta c r p$ where TGEV S gene fragments were constitutively expressed.

To express site $\mathrm{D}$ an oligonucleotide of $90 \mathrm{bp}$ was obtained by hybridization of two complementary oligonucleotides coding for the sequence ISCYTVSDSSFFSYGEIPFGVTDGPRYCYV. The blunt end oligonucleotide was cloned into expression plasmid pYA3048 in frame with $E$. coli labile toxin B subunit (LT-B) gene, under the control of Ptrc promoter ${ }^{10}$. A collection of recombinant plasmids named pYALT-D with different inserts was selected. Expression of site D by these constructs was determined by Western blot using site D specific MAbs.

To generate Ad5-TGEV recombinants TGEV $S$ gene fragments cloned into pBluescript $\mathrm{SK}^{-}$were subcloned into plasmids pSV2X3 or pSV2X4 containing an SV-40 based expression cassette. These cassettes were flanked by right end Ad5 sequences, by inserting them into a unique XbaI site present in pAB14 or pFG144K3 plasmids ${ }^{7,11}$. By cotransfecting these plasmids and plasmid pFG173 (which carries a functional left end of Ad5) into 293 cells, recombinant Ad5-TGEV chimeras were selected. Expression of $S$ protein fragments was determined by Western blot, and immunoenzymatic assays, and their immunogenicity was evaluated by oronasal and intraperitoneal administration to hamsters. The immune response to TGEV was tested by RIA and neutralization.

\section{RESULTS AND DISCUSSION}

\section{Antigenic determinants potentially involved in protection}

Since all TGEV neutralizing antibodies were specific for the $S$ protein and this antigen also mediates the binding of TGEV to host cells, its potential role in protection was 


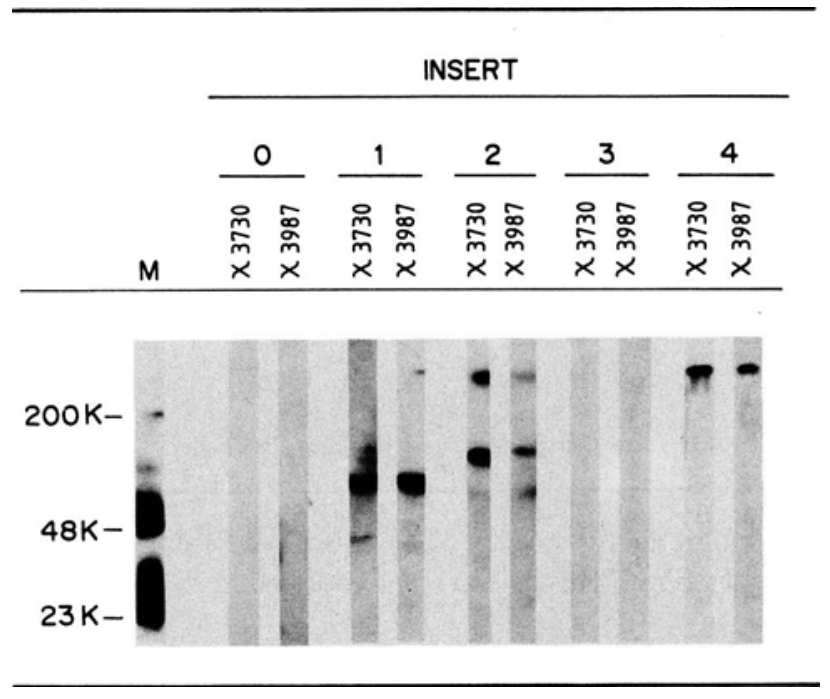

FIGURE 2. Western blot analysis of the recombinant antigens expressed in $S$. typhimurium. The indicated Salmonella was transformed with plasmid pYA292 with no insert (0) or with plasmids pYATS1, pYATS2, pYATS3 or pYATS4, containing the left end (1), middle (2), right end (3), or the whole S gene (4), respectively. M, TGEV proteins used as molecular weight markers.

studied. The amino acids contributing to the four antigenic sites of $S$ glycoprotein were: site A, 538, 543, 586, and 591; site B, 97 and 144; site C, 48 to 52; and site D, $385^{5}$. Site A was the most conserved one, followed by sites D, B and C. Since sites A, B, and D induced TGEV neutralizing antibodies, special attention was paid to $S$ protein fragments coding for these sites. Nevertheless, other antigenic domains of $S$ protein were also expressed both in Salmonella and Ad5, since it has been reported that protection can also be provided against some viral infections by non-neutralizing antibodies. Site D, which is linear and glycosylation independent, was synthesized in three forms (Figure 1). These peptides induced TGEV neutralizing antibodies in rabbits ${ }^{12,13}$. One of them (Fig. 1B, peptide a) was selected for its expression, genetically linked to LT-B.

\section{Induction of TGEV-specific antibodies by expressing antigenic determinants of $S$ protein using $S$. typhimurium}

The whole $\mathrm{S}$ glycoprotein or overlapping fragments including the $\mathrm{NH}_{2}$ - end, the middle, and the carboxy-terminus were expressed in avirulent forms of $S$. typhimurium $\chi 3987$ (Table 1, Fig. 1). The relative amount of antigen expressed by the different recombinants is summarized in Table 1 . In S. typhimurium $\chi 3987$, with constitutive expression, plasmids pYATS1 and pYATS4, coding for the $\mathrm{NH}_{2}$-end and the whole $\mathrm{S}$ protein, respectively, expressed products with low toxicity. Stability of these expression systems was analyzed after 10,25 , and 50 generations in vitro. After 50 generations $90 \%$ of the bacteria transformed with both pYA-TS1 and pYA-TS4 carried correct plasmid, and $60 \%$ and $20 \%$ of the bacteria, respectively, expressed the S-protein antigen. If the same level of stability is maintained in vivo the amount of antigen expressed could be enough to induce a protective immune response. To further increase the stability of plasmids coding for $S$ protein, a smaller oligonucleotide, coding for 30 amino acids which include antigenic site $D$, was genetically linked to heat labile $E$. coli enterotoxin (LT-B). This non-toxic subunit has been described as a strong immunogen, when administered into the gut via the oral route, in 


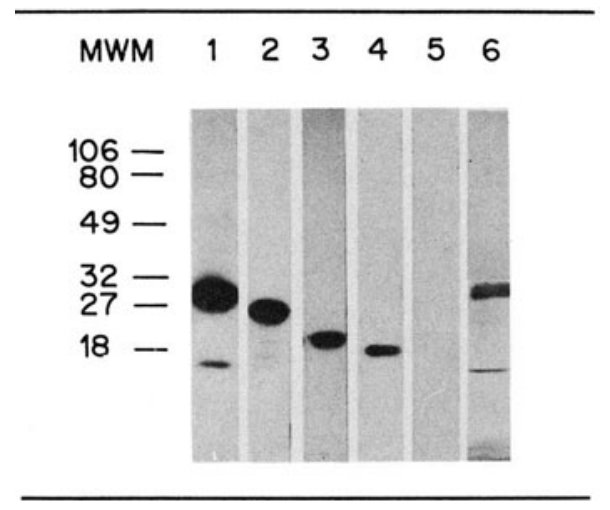

FIGURE 3. Western blot analysis of the LT-B site D recombinant products expressed in S. typhimurium. Salmonella $\chi 3730$ was transformed with plasmids pYA3048 asd $^{+}$including LT-B gene and one to four copies of a 90 bp oligonucleotide coding for site D (lines 1 to 4, respectively). The antigenic expression was analyzed with site D specific MAbs. Line 5 shows the expression in bacteria transformed with pYA3048 plasmid with no insert coding for site D. The two subunits (A, and B) of purified E. coli LT toxoid (ICN, Ohio) were analyzed in parallel and identified by silver staining (line 6). MWM, molecular weight markers.

TABLE 2. Colonies of $S$. typhimurium $\chi 3987$ expressing site D from TGEV S protein as a fusion product with LT-B

\begin{tabular}{lccc}
\hline & & \multicolumn{2}{c}{$\begin{array}{c}\text { Positive colonies (\%) } \\
\text { Number of generations }\end{array}$} \\
\cline { 3 - 4 } Plasmid & Fusion product MW & 25 & 50 \\
\hline pYALT-D I & high & 100 & 100 \\
pYALT-D II & intermediate-high & 100 & 77 \\
pYALT-D III & intermediate-low & 100 & 90 \\
pYALT-D IV & low & 100 & 100 \\
\hline
\end{tabular}

microgram amounts of protein, or when delivered to the GALT by attenuated Salmonella strains. LT-B induces an immune response preferentially with immunoglobulins of IgA isotype. Site D was genetically coupled to the carboxy-terminus of LT-B using plasmid pYA3048 as $d+$, under the control of Ptrc promoter. At least, four expression patterns of LTB-D recombinant antigens, with 30-, 27-22-, and 18-kDa, were selected in different bacteria (Figure 3). Each of these recombinant antigens probably contains one to four site D monomers per LT-B molecule. The stability of the expression of site $\mathrm{D}$ after 50 generations in these recombinants was close to $100 \%$ (Table 2). The low toxicity in bacteria of LT-B-D is of high interest, since site D induced TGEV neutralizing antibodies. The sequences of 30 amino acids, containing site D core, probably form loops by disulfide bridges between cysteines located 26 amino acids apart. These loops could result in high site D core exposure, which may help the induction of TGEV neutralizing antibodies. These fusion proteins formed heat sensitive pentamers which dissociate at $70^{\circ} \mathrm{C}$. Pentamer formation is 


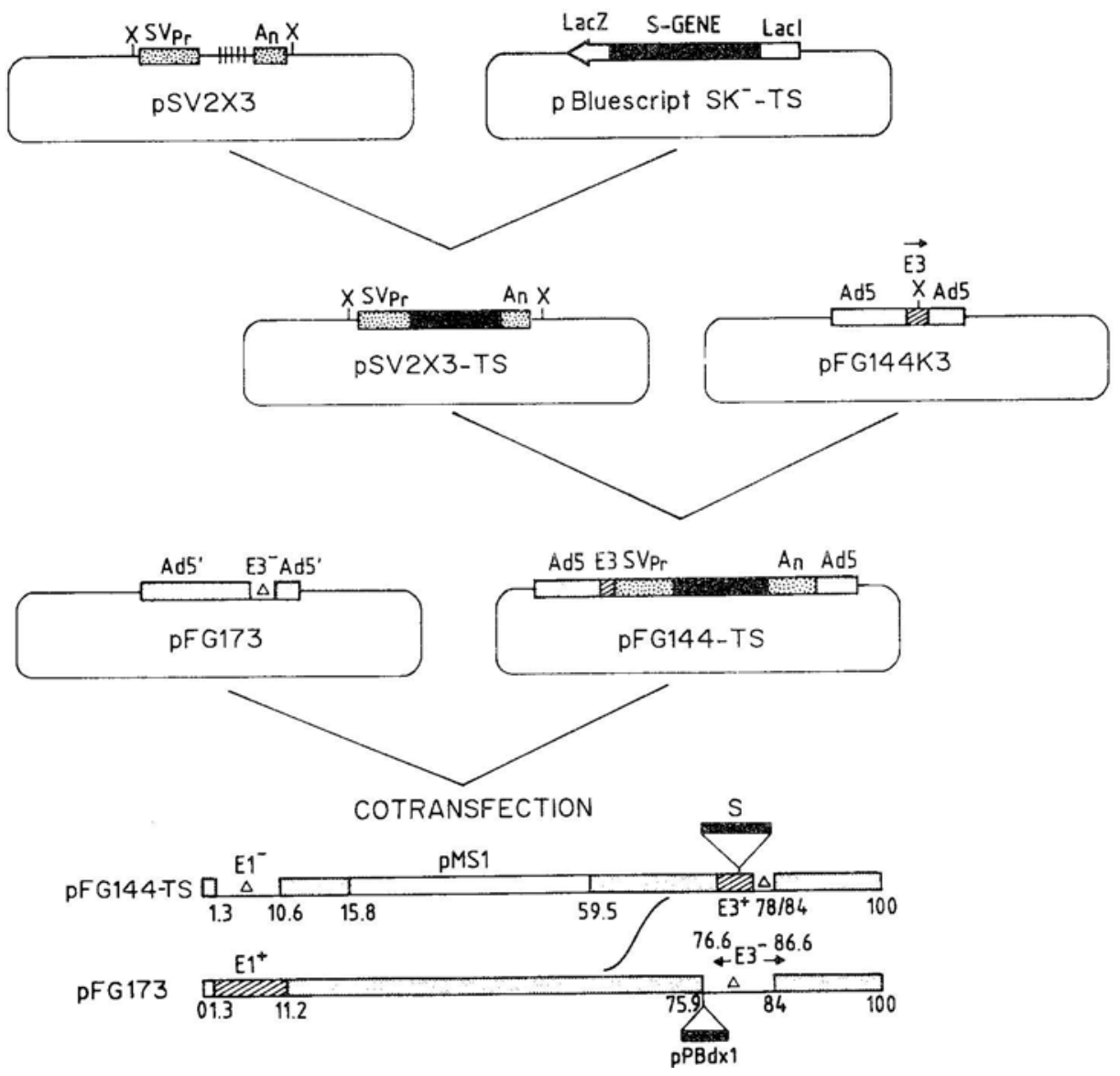

FIGURE 4. Construction of recombinant Ad5-TGEV expression vectors. TGEV S gene sequences (bold line) were cloned into Bluescript plasmid and inserted on pSV2X3 plasmid containing expression cassette with SV-40 promoter $\left(\mathrm{SV}_{\mathrm{Pr}}\right)$ and polyadenylation signals $\left(A_{n}\right)$. The expression cassette was flanked by Ad5 sequences by subcloning into pFG144K3 plasmid. Cotransfection of 293 cells with this plasmid and pFG173 plasmid containing a functional left hand Ad5 sequence generated infectious Ad5-TGEV chimeric viruses ${ }^{14}$.

required for the adjuvant activity of LT-B, since these complexes bind the ganglioside GM1 present in the surface of enteric epithelial cells, promoting antigen presentation to GALT. The recombinant protein LTB-site D forms aggregates of higher molecular weight, as determined by polyacrylamide gel electrophoresis in non-reducing conditions. These large complexes were dissociated by 2 -mercaptoethanol, suggesting that the aggregation was mediated by disulphide bridges. The immunogenicity of these complexes is being evaluated in vivo.

\section{Induction of an immune response to TGEV using Ad5 based vectors}

An Ad5 vector system has been used to express antigenic determinants of the $\mathrm{S}$ glycoprotein of TGEV. This eukaryotic vector may complement the $S$. typhimurium system, since sites $\mathrm{A}$ and $\mathrm{B}$, inducers of TGEV neutralizing antibodies, are glycosylation dependent. 
The Ad5 system is based on the homologous recombination between two plasmids, one that spans the left end of the Ad5 genome and another that spans the right end into which TGEVcDNA sequences were inserted (Fig. 4). TGEV S gene sequences (Fig. 5) were cloned into an expression cassette with an SV-40 promoter and polyadenylation signals. The expression cassette was inserted into the E3 region of Ad5 virus. Rescued chimeric Ad5-TGEV recombinants were cloned into two types of Ad5 vectors, according to the size of the heterologous genes which may be inserted in E3. This cloning was made into plasmids pFG144K3 (originating plasmids Ad-TS1 to -5 ) and pAB14 (which produced plasmids AdTS01 to -04). Plasmids pFG144K3 and pAB14 have deletions in the E3 gene of 1880 or $2686 \mathrm{bp}$, which allows the insertion of 4000 or $4800 \mathrm{bp}$, respectively, in the final recombinant Ad5 virus ?. Vectors derived from pAB14 should in principle leave enough room to clone the entire TGEV S gene. The antigenicity of the recombinant proteins was studied by Western blot and immunoadsorption, and the immunogenicity by oronasal and

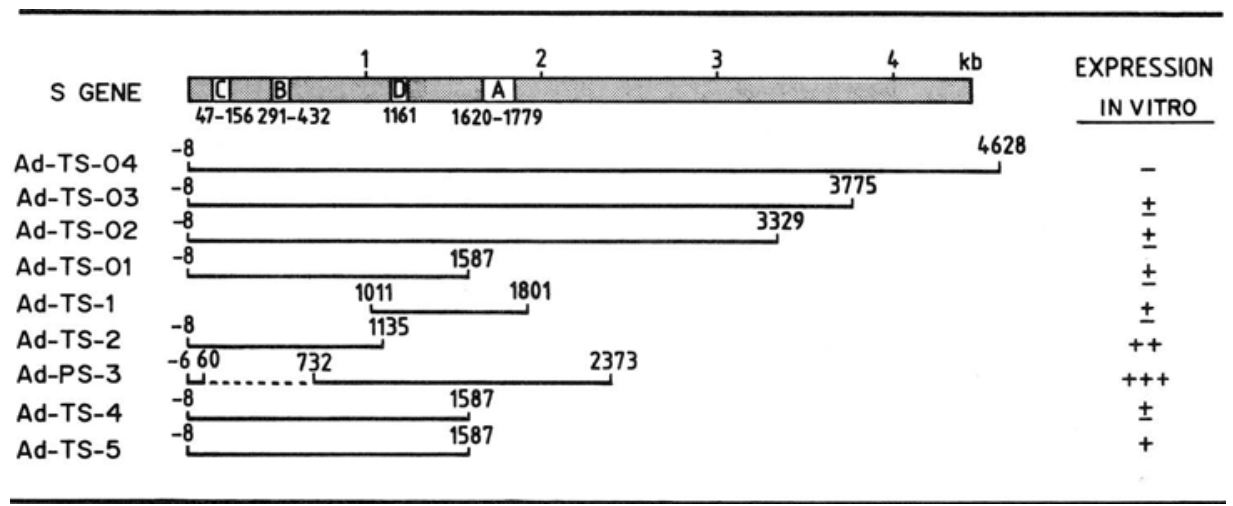

FIGURE 5. Recombinant AD5-TGEV constructed. The different segments of TGEV S gene cloned into Ad5 virus are shown. Numbers indicate the nucleotides flanking the inserts cloned. The dotted bar represents the $S$ gene, and the letters inside the bar the approximate location of the different antigenic sites. The relative antigenic determinants of TGEV $S$ protein expression levels are indicated.,+++ , and +++ , indicate $0.1,0.2$, and $0.4 \mu \mathrm{g}$ per $10^{6}$ cells.

intraperitoneal infection of hamsters, which are fully susceptible to infection by Ad5. Three Ad5-TGEV recombinants Ad-TS2, Ad-PS3, and Ad-TS5 (Table 4) gave substantial amounts $\left(0.1\right.$ to $0.4 \mu \mathrm{g}$ of protein per $10^{6}$ cells) ${ }^{14}$ of TGEV S protein fragments. Recombinant AdTS04, which codes for the whole S protein, was unstable and after three passages in 293 cells rearranged the DNA and lost the expression of $S$ glycoprotein. Recombinant viruses Ad-TS2, Ad-TS5, and Ad-PS3 were antigenic for site D specific MAbs. In addition, AdPS3, also expressed site A, as determined by Western blot analysis with site A specific MAbs. Both of these sites are the major inducers of TGEV neutralizing antibodies. Recombinant vectors Ad-TS2 and Ad-PS3 induced in hamsters, after oronasal and intraperitoneal immunization, TGEV specific antibodies as determined by RIA. Interestingly, recombinant Ad-PS3 also induced TGEV neutralizing antibodies which reduced viral infectivity by $10^{2}-10^{3}$-fold. These results indicate that recombinant Ad5-TGEV viruses could provide protection against TGEV infections. 


\section{ACKNOWLEDGEMENTS}

We thank Javier Palacín for technical assistance with animal handling. This work was supported by grants from the Comisión Interministerial de Ciencia y Tecnología (project BIO091-0710), European Communities (Science project SCI-CT91-0684-LNBE), NATO (project 900430-CRG), Fundación R. Areces, and the Natural Sciences and Engineering Research Council of Canada. C. Smerdou, C. Suñé, and J.M. Torres received fellowships from the Department of Education and Science.

\section{REFERENCES}

1. L.J. Saif and E.H. Bohl, Transmissible gastroenteritis, in: "Diseases of Swine," A.D. Leman, B. Straw, R.D. Glock, W.L. Mengeling, R.H.C. Penny, and E. Scholl, eds., Iowa State University Press, Ames, Iowa (1986).

2. I. Correa, G. Jiménez, C. Suñé, M.J. Bullido, and L. Enjuanes, Vir. Res, 10:77 (1988).

3. I. Correa, F. Gebauer, M.J. Bullido, C. Suñé, M.F.D. Baay, K.A. Zwaagstra, W.P.A., J. Gen. Virol. 71: 271 (1990).

4. C.M. Sánchez, G. Jiménez, M.D. Laviada, I. Correa, C. Suñé, M.J. Bullido, F. Gebauer, C. Smerdou, P. Callebaut, J.M. Escribano, and L. Enjuanes, Virology. $174: 410$ (1990).

5. F. Gebauer, W.A.P. Posthumus, I. Correa, C. Suñé, C.M. Sánchez, C. Smerdou, J. A. Lenstra, R. Meloen, and L. Enjuanes, Virology. 183: 225 (1991).

6. R. Curtiss III, S.M. Kelly, P.A. Gulig, and K. Nakayama, Selective delivery of antigens by recombinant bacteria, Curr. Topics Microbiol. Immunol. 146:35 (1989).

7. F.L.Graham, and L. Prevec, Adenovirus-based expression vectors and recombinant vaccines, in: "Vaccines: New Approaches to Immunological Problems," R.W. Ellis, ed.(1992).

8. G. Jiménez, I. Correa, M.P. Melgosa, M.J. Bullido, and L. Enjuanes, J. Virol. 60:131 (1986).

9. C.M. Sánchez, F. Gebauer, C. Suñé, A. Mendez, J. Dopazo, and L. Enjuanes, Virology 190:92 (1992).

10. E.K. Jagusztyn-Krynicka, J.E. Clarck-Curtiss, and R. Curtiss III, Infect. Immun. 61:1004 (1993).

11. A. Bett, F.L. Graham, and L. Prevec. Unpublished results.

12. W.P.A. Posthumus, J.A. Lenstra, W.M.M. Schaaper, A.P. van Nieuwstadt, L. Enjuanes, and R.H. Meloen, J. Virol. 64:3304 (1990).

13. C. Smerdou and L. Enjuanes, Unpublished results.

14. C.M. Sánchez, J.M. Torres, C. Suñé, F.L. Graham, and L. Enjuanes, Submitted. 